\title{
Transition Words in Academic Writing
}

\section{Bisera Plančić, Siniša Ninčevića}

This article is concerned with transition words and their use in academic writing. These words and phrases, also called linking words or connectives, relate sentences and paragraphs to eventually create a cohesive and coherent text. In order to illustrate how to logically organize information in writing, the authors give some examples of the usage of transition words at sentence and text levels. Mastering transition words is beneficial to all users who wish to improve their writing skills. As writing is one of the most important means of communication in Maritime English, the following examples are based on the textbooks that students use in their ESP class: "English for Maritime Studies "by T.N. Blakey that provides a rich source of target material, a paragraph from "Commercial Management for Shipmasters" by Robert L. Tallac, and The New York Times article by Paul Krugman. Students are encouraged to get acquainted with the function of transition words and expressions, which will serve as a fingerpost how to avoid their misuse or overuse and logically organize thoughts and ideas. The enclosed appendix includes a list of transition words and expressions according to their functions, alongside the selected example sentences which present transition words in action. The article is aimed at improving writing skills so essential in preparing for seafaring and many other careers.

\section{KEY WORDS}

$\sim$ Transition words

$\sim$ Writing

$\sim$ Structure

$\sim$ Cohesion

$\sim$ Coherence

University of Split, Faculty of Maritime Studies, Split, Croatia e-mail: bisera@pfst.hr

a. University of Split, Faculty of Philosophy, Split, Croatia e-mail: sinisa.nincevic@ffst.hr

\section{INTRODUCTION}

Academic writing poses a great problem to both native and non-native speakers of English. This primarily refers to written assignments for academic purposes such as academic essays, dissertations, theses, journal papers, etc. The task of mastering writing skills is complex in terms of syntax, semantics, and punctuation, which is essential for sense-making units in writing. This article, however, focuses on some words and expressions which should not be randomly used in written works since they are essential in relating sentences and paragraphs in order to make text forms more coherent. As they connect sentences and paragraphs, they are referred to as connectives or linking words that are typical of texts from a specialist area, as opposed to literary texts. Namely, the usage of transitional words is indicative of what text type is in question. Transitional words frequently occur in journal articles, theses, dissertations, newspaper articles, etc. However, they are not as common in literary works. Some connectives are non-semantic words as their function is to relate sentences (e.g. conjunctions and, because, but). On the other hand, others occur both at sentence and text levels as adverb phrases (consequently, hence, however, nevertheless) or prepositional phrases (in other words, on the contrary, in conclusion). These are also called textual connectives since they make sentences part of the text. Connectives can be also viewed in terms of text level as language devices or signals for sentence or clause reference between what has been said (anaphoric reference such as the foregoing) and what is being said (cataphoric reference such as the following, as follows, and thus), i.e., to point back or forward in written discourse. Some signals can be both anaphoric or cataphoric (here, it, and this). In this respect, the aim of this article is to provide the ESL learners with some useful expressions indispensable for study and academic work as to the writing process. Transitional or linking words should be carefully employed in order to create a 
well-structured text. This article is tailored to the needs of those who aspire to improve their text building skills. For the foregoing reasons, some transition words are presented at sentence level, based on the textbook "English for Maritime Studies" by T.N. Blakey. The enclosed appendix includes a list of transition words grouped according to their function (addition, reason or cause, consequence or result, qualification and concession, emphasis, summery, conclusion etc.). A paragraph by Robert B. Tallac and an article by Paul Krugman are, respectively, illustrative of their usage at text level.

\section{COHERENCE AND COHESION IN WRITING}

When writing it is very important to choose a suitable pattern in which to convey information in order to help the reader understand relationships between ideas and thoughts. When this has been achieved, it means that there are clear logical transitions and connections binding the text into a coherent unit. The lack of cohesion (connectivity) and coherence (sensemaking) in writing is not only caused by disjointed thoughts and ideas but also by the misuse of transition devices such as connectives or linking words. These words assist us in connecting sentences since they are essential to sense-making units (paragraphs) in terms of getting the reader's attention in the introductory paragraph, elaborating and supporting their ideas in the main text, and restating the main idea in the concluding paragraph. When properly used, transition words will allow an unimpeded reading process, i.e., an effortless movement back or forward through different paragraphs of the text. Of course, in achieving cohesion we must not underestimate the importance of lexical coherence, which includes connective devices such as pronouns, word repetition, synonyms and antonyms, hyponymy and various other transitional markers, even punctuation marks.

The use of devices varies with genres as the same style cannot be applied to all writing assignments. Prior to the study of various types of transition words, students need to be exposed to different text structures to become familiar with organisation patterns. Some structures require information to be expressed either in chronological order, in order of importance or sequence. Sometimes the writing is about a problem that is described and a solution is proposed, or the results of something are explained, or similarities and differences are discussed. All of these require specific structure patterns that help authors to communicate their ideas.

After the students are able to identify and choose structures that complement the ideas they wish to convey, it is important that they acquire receptive and productive knowledge of transition words. All the nuances of transition words should be observed since they usually fall into more than one category, as shown in the appendix attached to this article.

As most of the linking words are not as commonly used in spoken language, it is only through writing and reading that their meaning can be properly acquired. Inaccurately used, these language devices may lead to text misinterpretation or the utter failure to understand the information conveyed by the text.

\section{LINKING WORDS (based on textbook by T. N. Blakey "English for Maritime Studies")}

In his textbook "English for Maritime Studies", T. N. Blakey pays great attention to linking words and their usage gradually unfolding the most important relationships within the text and its connecting parts. We can say that linking words appear throughout the book as a guiding theme. With numerous examples at sentence and text levels, he successfully explains and illustrates how to achieve cohesion and coherence in the writing process.

The author starts with the most frequent connecting words such as and, or, but and their use in many examples. Some of them are:

\section{- $\quad$ Passenger liners carry passengers and cargo.}

He explains that in this case and means they carry both and suggests at the same time.

- Cargo liners are designed to carry containerized or conventional cargoes.

Or here adds an alternative.

- Merchant ships are classified by type and trade, but warships are classified by type and size.

In examples with both...and; not only...but also, additions to connecting words tell us to expect an addition or an alternative a little later:

\section{- $\quad$ Some ferries carry both passengers and cars. \\ - Some ferries carry not only passengers but also cars.}

Alternatives can also be linked by either...or; neither...nor (negative) as follows:

\section{- The sailor had neither money nor his passport.}

Unit after unit Blakey continues with the connectives in his efforts to show how their effective use may improve communication in students' writing. There are plenty of examples and exercises for students to draw examples from and use them effectively in their own sentences.

Under the heading "Logical connectives" (ii), Blakey lists because, therefore and however which express reason or cause, consequence or result, qualification and concession.

- $\quad$ Passenger liners have high superstructures because they need a large number of decks. 
- Many ferries are designed to carry vehicles; therefore, they have doors at the bows or stern.

- Multi - deck vessels usually carry general cargo, however, some carry containers as well.

In Unit III, textbook readers become familiar with time relaters and learn the use of sequence words to show that events happen one after the other, i.e., to show the order of facts. These words are usually put at the beginning of the process or event that they introduce. These are: first, then, next, after that, afterwards, later, eventually, finally. Sequence words can be used in any order except for first and finally.

\section{- $\quad$ First, I went to college. - Then, I went to sea.}

Then, he introduces time relaters that are used when we want to show that one event takes place at the same time as another. These events may be linked using when, while and as.

- When the ship is launched, the crowds cheer.

- $\quad$ Constant checks are made, while the ship is being built.

When two actions are closely connected, as can be used instead of while:

- $\quad$ As the sun rose, the sky became lighter.

When we want to show the limit of an action, we use until:

- The Chief Officer stayed on watch until 0800.

When one event happens at the same time as another, when/while can sometimes be replaced by during:

- During the launching of the ship, tugs stand by ready to help.

There are many ways to connect cause and effect. Blakey lists the following causal verbs and examples: causes, results in, give rise to, produces, is the cause of, is one of the causes of.

Sea water causes corrosion. If the effect is put first the links are: result from, is due to, arises from, is the result of: Corrosion is caused by sea water.

When there are clauses to be linked we may use causal verbs, -ing clauses, and connecting words, such as consequently:

- $\quad$ The engines reduced speed, causing the ship to slow down.

- The engines reduced speed, consequently the ship slowed down.

Purpose for doing something can be expressed by using so as, in order, so that
- The ship docked in order to take on fuel.

- He ran so as not to be late.

- The captain looked through his binoculars so that he could see more clearly.

Comparisons can be made by links such as as... as and the negative not so/as...as

- The Deck Department is as important as the Engine Department.

- The Atlantic Ocean is not as big as the Pacific Ocean.

Finally, Blakey moves from sentences to paragraphs to show how the relationship between paragraphs can be made clearer by linking paragraphs and bridging sentences. He gives three basic types of paragraphs and how they may be linked:

Introductory paragraph:

- $\quad$ There are a number of reasons for wear in cylinder liners. Wear may be due to friction, corrosion and abrasion. Each of these may have a number of causes.

\section{Bridging sentence:}

- Having discussed the causes of frictional wear, let us go on to consider the reasons for corrosion.

\section{Summary paragraph:}

- We have shown, then, that cylinder liner wear is caused by friction between the liner and the piston ring, by corrosion - mainly from burning heavy fuels - and by abrasion from the products of wear corrosion and combustion.

\subsection{Transition words in text examples}

The selected paragraphs stand as two examples of the usage of transition words in action at text level. The Club Correspondents on marine insurance by Robert L. Tallac is intended for subject-area specialists. The New Political Correctness by Paul Krugman is an opinion piece published in The New York Times. The former is an example of the marine insurance register and the latter illustrates one of many journalism styles.

The transition words used in these texts are classified as in the enclosed appendix that contains the expressions grouped into various categories that explain their functions. Each category provides a number of transition words employed to express comparison contrast, exception, reason; also to qualify and emphasize, rephrase or add ideas. Without them our texts would read like a series of incoherent ideas. However, they should be properly used, because we can see from the texts that follow, transition words only signal the link which is usually achieved by other transition devices that are essential for proper sequence and structure of ideas. 
THE CLUB CORRESPONDENTS (Robert L. Tallac: Commercial Management for Shipmasters)

The club correspondents are probably the master's main point of contact with his P\&I Club. A club will establish an extensive network of Correspondents, people with maritime-related legal or commercial skills, located in ports throughout the world. The Correspondents are not the agents (either of the Club or its managers) - (alternative) but (contrast) independent individuals and (addition) companies. Indeed (emphasis, support), many Correspondents are used by more than one Club. Perhaps their greatest asset is knowledge of the local maritime trade coupled with (addition) a good understanding of how Club cover works. Although (contrast) the Club Correspondents should formally be appointed and briefed by the Club, their role too (addition) is loss prevention. In such cases (reference), early involvement of expert assistance is frequently the master's wisest course of action. However (contrast), he should bear in mind that they may be independent representatives, rather (contrast) than agents. Even (emphasis) in relation to non-P\&I matters, the Correspondents can be a useful source of information.

THE NEW POLITICAL CORRECTNESS (Paul Krugman: The New York Times)

Remember the furor over liberal political correctness? Yes, some of it was over the top - but (addition) it was mainly silly, not something that actually warped our national discussion.

Today, however (qualification), the big threat to our discourse is right-wing political correctness, which - unlike the liberal version - has lots of power and money behind it. And (addition) the goal is very much the kind of thing Orwell tried to convey with his notion of Newspeak: to make it impossible to talk, and possibly even (emphasis) think, about ideas that challenge the established order.

Thus (consequence, result), even (emphasis) talking about "the wealthy" brings angry denunciations; we're supposed to call them "job creators". Even (emphasis) talking about inequality is "class warfare."

And then (sequence) there's the teaching of history. Eric Rauchway has a great post about attacks on the history curriculum in which even (emphasis) talking about "immigration and ethnicity" or "environmental history" becomes part of a left-wing conspiracy. As (similarity) he says, he'll name his new course "US History: The Awesomeness of Awesome Americans." That (restatement), after all (summary), seems to be the only safe kind of thing to say.

Actually (conclusion), this reminds me of an essay I read a long time ago about Soviet science fiction. The author - if anyone remembers where this came from - noted that most science fiction is about one of two thoughts: "if only", or "if this goes on." Both (reference) were subversive, from the Soviet point of view: the first (sequence) implied that things could be better, the second (sequence) that there was something wrong with the way things are. So (consequence, result), stories had to be written about "if only this goes on", extolling the wonders of being wonderful Soviets. And now (reference) that's happening in America.

\section{CONCLUSION}

- The lack of flow and cohesion greatly reduces the value of the most brilliant ideas and thoughts. The ideas in this article have been developed to aid students in connecting their ideas logically and to give them a required structure. Transition words are important cohesive devices that put ideas in order and express their relationship. They help students overcome the problem of structure and coherence if they know how to properly use them in their writing. Students should also be aware of various lexical ties they can use instead of conjunctions and connectives. To proceed from awareness of transition words to their receptive use (understanding) and finally production (correct writing), users ought to be motivated to read as much as possible as it is through reading that they may fully grasp the subtle differences in the meaning of various linking words and phrases, as well as find many other ways to achieve the desired cohesion of their texts. This will help them avoid the misuse and overuse of linking words, which is one of the most common style errors in non-native speakers' writing assignments.

\section{REFERENCES}

Blakey, T. N., (1997), English for Maritime Studies, Oxford: Pergamon Press.

Frank M., (1993), Modern English: A Practical Reference, New Jersey: Regents/ Prentice Hall.

Hayard K., Wilcoxon H.C., (1994), Connectives in Context, English Teaching Forum, 32 (1), pp. 20-23.

Langan, J., (1996), College writing skills, New York: McGraw-Hill.

Liu, D., (2000), Writing cohesion: Using content lexical ties in ESOL, English Teaching Forum, 38 (1), pp. 28-33.

McCarthy, M., (1991), Discourse analysis for language teachers, Cambridge: Cambridge University Press.

Quirk, R. and Greenbaum, S., (1977), A University Grammar of English, Longman.

Tallac, Robert L., (1996), Commercial Management for Shipmasters, London: The Nautical Institute London.

Velčić, M., (1987), Uvod u lingvistiku teksta, Zagreb: Školska knjiga.

Cohesion: linking words and phrases, available at: http://library.bcu.ac.uk/learner/ writingguides/1.33.htm [accessed 15 March 2014.].

Linking words and phrases, available at: http://www.flinders.edu.au/slc_files/ Documents/Brochures/linking_words_phrases.pdf [accessed 20 February 2014.].

The New Political Correctness, availabe at: http://krugman.blogs.nytimes. com/2012/05/26/the-new-political-correctness/?_php=true\&_type=blogs\&_r=0. [accessed 25 February 2014.]. 


\section{APPENDIX}

Transition words

\section{Addition}

And, too, similarly, likewise, additionally, in addition, further, furthermore, coupled with, what is more, moreover, equally important, the following, last but not least, also, but also, apart from this, as well as, besides, nor, not only, but also.

- As well as being a world-class hub port for containers and new vehicles, Southampton handles a wide range of other trades.

- In addition /Furthermore / Moreover, students need more time to study.

- We are concerned not only by the cost but also by the competition.

- Besides, I didn't really like that job.

- $\quad$ Last but not least, let's talk about our destination.

\section{Exception}

Aside from, barring, except, excepting, other than, outside of, save for, exclusive of, excluding.

- $\quad$ Excluding few scratches, he's fine.

- Apart from/aside from the final presentation, everything went well.

- Barring / except for / unless there are accidents, they should arrive on time. Is the total exclusive of service charge?

- They found all the lost relatives save (for) one.

\section{Time/sequence}

Finally, eventually, firstly, at first, in the first place, in the second place, in the end, lastly, second, secondly, later, next, at first, first of all, first, second, quickly, currently, earlier, now, eventually, in the future, in the past, later on, to begin with, at the same time, in a moment, at the present time, from time to time, sooner or later, whenever, up to the present time, as soon as, as long as, afterward, concurrently, previously, subsequently, formerly, immediately, in the meantime, the former ... the latter, to begin with, in due time, without delay, all of a sudden, at this instant, simultaneously, for now, for the time being, the next step, in time, in turn, meanwhile, when, as soon as, until, by the time, then, soon, while, earlier, afterward, in the end, in conclusion, with this in mind.

- Next, l'd like to show you some pictures. Maritime law and insurance are both covered in the course. The former is studied in the first term and the latter is studied in the final term. The doctor will see her again tomorrow. Meanwhile, she should rest as much as possible. Feel free to call whenever you need help.

\section{Qualification/concession}

Admittedly, in spite of, after all, naturally, all the same, nevertheless, although, no doubt, although this may be true, nonetheless, at the same time, notwithstanding, besides, only, despite, still, doubtless, under certain circumstances, even if/though, up to a point, even so, while, yet, as though, however, despite the fact that/this.

- However you look at it, cricket is a boring game.

- Despite the fact that he was well known, he was a very modest man.

- $\quad$ Although tankers sail on fixed routes, they do not carry passengers.

- $\quad T h e y$ are spending money as though there's no tomorrow.

- The salary offered was very low; notwithstanding, there were more than three hundred applications for the job.

\section{Contrast/ comparison}

But, despite, in spite(of), even so, in contrast, in spite of this, nevertheless, on the contrary, still, whereas, yet, but, however, also, like, too, by the same token, instead, rather, similarly, as if, while, in the same way, mind you, equally, although, even though, though, as well as, both... and, compared to, in the same way, likewise, unlike, on one hand, on the other hand, on the contrary, nonetheless, in contrast, in contrast to, conversely, by comparison, in common with, in like manner, on the contrary, otherwise

- In spite of the present recession, the long-term economic outlook is optimistic. The term "non-contiguous trade" means trade between the contiguous forty-eight States on the one hand, and Alaska, Hawaii, Puerto Rico, and the insular territories and possessions of the United States on the other hand, and trade from any point in Navy oilers were named for rivers, and so a distant Australian river (that just happened to have the same name as the host state) was chosen; but by the same token, USN cruisers were named for cities, not other ships. He is unlikely ever to get promoted and I know he is keen to return home at the earliest opportunity. Nevertheless, he will be expected to fulfil his contract and remain with us until the end of the summer. Unlike Europe, the USA has cheap petrol. My mother always had poor health. In spite of this, she was always cheerful.

\section{Cause/ Effect/consequence/ result}

Accordingly, consequently, as a consequence, as a result, because, because of this, for this reason, hence, in consequence, in order to, owing to this, since, so, so that, therefore, thus so, then, therefore, on account of, then, therefore. 
- Work has become a lot more efficient since computers are now widely used. What is the procedure in case both of the engines fail?

- You'd better go now, otherwise you'll miss your bus.

- Leave early so that you come on time. Multi-deck vessels have "tween decks because these help stowage. Vessels are designed for many purposes and therefore their type and size vary considerably. She complained of stiffness in her joints. Accordingly, she was admitted to hospital for further tests. Her health had deteriorated significantly. As a result/ On account of this/ for this reason, she decided it would be best to retire. The company are expanding. Therefore / So / Consequently / As a result, they are taking on extra staff. They are learning English in order that they can study in Australia.

\section{Exemplifying/illustration}

For example, as an example, for instance, such as, thus, as follows, namely, especially, including, in this case, particularly, specifically, in this way, for one thing, in other words, as an illustration, to exemplify, markedly, chiefly, in particular, illustrated with /by, as revealed by.

- Exams, such as final term exams, are very important. For example, the government has only recently decided to raise taxes. In this way, they hope to create new jobs. This is not good, particularly in the areas of leadership and communication. Southampton handles a wide range of other trades including cruise ships, grain and fruit and fresh produce, liquid bulks and project cargoes.

\section{Generalisation}

As a rule, for the most part, generally, in general, normally, on the whole, in most cases, usually, as usual, broadly speaking, to some extent, mostly, above all, chiefly, essentially, largely, primarily, generally speaking, broadly speaking, ordinarily, by and large, to a great extent, apart from, except for.

- Essentially, what you are suggesting is that we should make changes in our policy. Broadly speaking, I agree with what's just been said. By and large/Generally speaking/On the whole, jobs traditionally done by women are paid at a lower rate than those traditionally done by men.

Restatement/ reformulation/ clarification/ repetition

To put it differently, in other words, once more, again and again, over and over, to repeat, as stated, to retell, after all, as one might expect, clearly, it goes without saying, naturally, obviously, of course, surely, namely, that is, i.e., that is to say, in short, in brief, all in all, again, altogether, in fact, in particular, in simpler terms, to review, to rephrase it, to paraphrase, to reconsider, to clarify, to explain, to outline, to summarize, in essence, or rather, this means, to be more precise, to put it another way, in a sense.

- $\quad$ The worldwide web, that is, the Internet is a valuable research tool. I don't altogether agree with them. We need to concentrate on our target examinees, namely students aged between 19 and 21. Do you have the right work experience and skills? In other words, can you do the job? What he said, in essence, was that he can't support our actions and will resign.

\section{Attitude}

Admittedly, certainly, fortunately, luckily, oddly enough, strangely enough, undoubtedly, unfortunately.

- $\quad$ Admittedly, I should have done more and filed a complaint in this legal matter. It is undoubtedly the most harrowing documentary I have ever seen. Oddly enough(strangely enough), NASA officials failed to regard the warning signs of imminent danger, which eventually led to the disintegration of the U.S. space shuttle Columbia.

- $\quad$ Luckily, all the passengers were evacuated from the sinking vessel.

\section{Reference}

Mainly, particularly, in particular, as follows, mostly, chiefly, namely, for instance, notably, for example, or, in other words, such as, including, that is.

- We are concerned about many aspects of her life - her health, mainly.

- $\quad$ Organise the text as follows - introduction, body text, and conclusion.

- Maritime safety issues have been addressed, in particular for the large passenger ships now being built.

- Attracting investors, most notably well-reputed financial houses, is essential for a country's economy.

- The island of Hvar chiefly attracts upscale tourists.

- It is important to consider all the factors, including the weather. The sinking of the Titanic is, for instance, one of the most infamous accidents in history. 


\section{Summary/ conclusion}

Finally, briefly, in brief, in conclusion, in short, overall, so, then, to conclude, to sum up, after all, all in all, all (things) considered, therefore, by and large, in any case, in any event (at all events), in fact, usually, on the whole, altogether, in general, at last, consequently, lastly, thus, as a consequence, in either case, in closing, in sum, to summarise, in summary, in essence, in a nutshell, in the final analysis, in the long run, on balance, ordinarily, as can be seen, generally speaking, as shown above, given these points, as has been noted, in a word, in my opinion, for the most part, obviously, ultimately, definitely.

- In any event, she did try to set aside some money every month. To sum up, the situation has improved since the last inspection. Briefly, the argument was caused by his unwillingness to pay for services. Consequently/As a consequence, they eat too much junk food. Ultimately, she'll have to make the decision herself.

\section{Purpose/ condition}

In that case, then to, so, in order to, so as to, in case, provided that, providing, given that, unless, only / even if, so that, owing to, in as much as, as long as.

- I would prefer not to share a room unless I have to. You should take an umbrella in case it rains. We turned on all the lights so as to see well. He behaved like a gentleman in order to impress his hosts. In the event that he doesn't call by noon, we'll have to leave without him. I would like to reserve a place, provided that the safety of the trip can be guaranteed. You can come to work any time as long as/ provided (that)/providing you complete everything you have to do.

\section{Emphasis}

Especially, even, in detail, mainly, notably, above all, particularly, singularly, with attention to, chiefly, in particular, significantly, undoubtedly, indeed, obviously, generally, it should be noted, admittedly, in fact, clearly, importantly, of major interest, to culminate, in truth, the climax of, to add to that, without question, unquestionably, as a result.

- $\quad$ Admittedly, it is rather expensive but you need it so much. It should be noted that this article examines only written communication. There is undoubtedly a great deal of truth in what you've been telling us. They chose a singularly inappropriate moment to discuss the issue of money. It was unquestionably something that had to be done.

\section{Inversion for emphasis}

Never, nowhere, not for one minute, not since, not until, never gain, rarely, seldom, hardly, no sooner, not only, at no time, in no way, on no account, should, had, were.

- Had I known they were in town, I would have phoned them.

- $\quad$ Never have I seen such a huge place. Only after years of practice could I perform the manoeuvre myself. Rarely do you meet a man of such integrity. No sooner had they secured this ship than they spotted a second French vessel. 